\title{
小鼠发情周期卵泡发育动态及其对超数排卵的影响
}

\author{
朱 娜，贾洪响，刘晓坤，赵晓娥，魏 强，马保华* \\ （西北农林科技大学 动物医学院 农业部动物生物技术重点实验室，陕西 杨凌 712100)
}

\begin{abstract}
摘要: 该文探讨了小鼠发情周期中阴门状态、阴道脱落细胞类型变化规律、卵泡发育规律及其相互关系, 并 比较了发情周期不同阶段的超排效果。结果表明, 采用阴门状态观察法和阴道脱落细胞涂片法, 能有效判断小鼠 发情周期阶段。卵巢组织切片观察结果表明, 在发情周期不同阶段, 小鼠的卵泡发育和黄体的生成与消退存在明 显的规律性变化; 小鼠发情周期中，其阴门状态、阴道脱落细胞种类及卵泡发育动态之间存在相关关系; 发情周期 不同阶段开始超排的小鼠, 其配种见栓率和回收胚胎平均数均存在明显差异, 发情前期显著优于发情后期与间情 期 $(P<0.05)$, 并高于发情期, 但差异不显著 $(P>0.05)$, 即阴门状态观察法与阴道脱落细胞涂片法均可用于小鼠发情 周期阶段的判断，发情前期为最适宜的小鼠超排时期。
\end{abstract}

关键词: 发情周期; 阴道脱落细胞; 卵泡发育; 超数排卵; 小鼠

中图分类号: Q492; Q954.431; Q959.837 文献标志码：A＼cjkstart文章编号：0254-5853-(2012)03-0276-07

\section{Measuring the estrus cycle and its effect on superovulation in mice}

\author{
ZHU Na, JIA Hong-Xiang, LIU Xiao-Kun, ZHAO Xiao-E, WEI Qiang, MA Bao-Hua* \\ (Key Laboratory of Animal Biotechnology, Ministry of Agriculture, College of Animal Veterinary Medicine, Northwest A \& F University, Yangling 712100, China)
}

\begin{abstract}
This study compares superovulation efficiency during different stages of the estrus cycle in mice by investigating the pudendum appearance, vaginal epithelial cell type, and the follicular development dynamics, in relation to the estrus cycle. We determined the stages of the estrus cycle by observing the pudendum and making vaginal smears of the Kunming mouse, and ascertaining the follicular development by making paraffin sections. Based on the observation, mice in stages of proestrus, oestrus, metoestrus and dioestrus were superovulated respectively, and their follicular developments and embryo collection results were tracked to ascertain the appropriate estrus cycle stage for superovulation. Our data showed that pudendum appearance and vaginal smears could effectively distinguish different stages of the estrus cycle and that ovarian tissue observation showed that follicular development, corpus luteum formation and luteolysis were regular during the estrus cycle. Likewise, during the estrus cycle of the Kunming mouse, pudendum appearance, vaginal epithelial cell type and follicular development were relational to one another. Superovulating mice in different stages of the estrus cycle showed marked differences both in pregnancy rate and average number of embryos collected. Proestrus was significantly better than metoestrus and dioestrus $(P<0.05)$, and better than oestrus, but the difference between them was not significant $(P>0.05)$. We suggest that pudendum appearance and vaginal smears can be used to distinguish estrus cycle stages and that proestrus is the optimal stage of the estrus cycle for superovulation.
\end{abstract}

Key words: Estrus cycle; Vaginal epithelial cell; Follicular development; Superovulation; Mouse

小鼠因其繁殖率高、繁殖周期短等特点被常用 于生物医学研究, 尤其是肧胎生物学和肧胎工程研 究(Brooke et al, 2007; Ding et al, 2007; MartínCoello et al, 2008)。超数排卵技术作为在同一时间 段获得足够数量卵母细胞或肧胎的主要手段之一, 是开展胚胎生物学和胚胎工程研究的基础(Chen et al, 1991; He et al, 1999, 2005)。

小鼠超排效果除受小鼠日龄和超排激素剂量 影响之外(Cui et al, 2012; Yang, 2007), 主要受超排 注射促性腺激素时小鼠所处发情周期阶段的影响, 但国内外对于小鼠超排的适合发情周期阶段所获 得的研究结果并不一致, 如 Fu et al (2005) 研究表

收稿日期: 2012-02-24; 接受日期：2012-03-17

基金项目：中国科学院战略性先导科技专项(XDA04020222-03)

*通信作者(Corresponding author), 马保华(1965-), 博士, 教授, 博士生导师, 主要从事动物细胞与胚胎工程研究。E-mail: mabh@nwsuaf.edu.cn 第一作者简介: 朱娜(1986-), 在读硕士, 主要从事动物胚胎工程研究。E-mail: zhuna1119@126.com 
明, 发情前期 ICR 小鼠超排后, 其见栓率、平均可 用胚胎数均高于其他发情周期阶段的小鼠; Guo et al (2006)对昆白系小鼠的超排后, 结论为在小鼠发 情前期的初期和间情期后期超排效果较好且两者 差异不显著; 而 Redian et al (1994)和 Tarín et al (2002) 在不同品系小鼠的超排中则证明, 发情期超 排小鼠效果最好, 发情后期和间情期超排效果较 差。由于处于发情周期不同阶段的小鼠, 其卵泡发 育情况及体内激素分泌存在差异(Palermo，2007)， 根据小鼠发情周期的卵泡发育规律和生殖内分泌 变化，可将小鼠发情周期分为发情前期、发情期、 发情后期和间情期 (Redian et al，1994)，其外部表 现为阴门状态的周期性变化 (Nagy et al, 2002)。在 小鼠超排研究中一般根据小鼠阴门状态的周期性 变化对发情周期阶段进行判断, 但由于小鼠的品系 或个体差异, 其发情周期各阶段长短、阴门状态变 化存在差别, 导致对其阴门状态的观察结果有所差 异。上述研究结果的差别, 除了所用促性腺激素来 源和小鼠品系的不同, 各研究者所采用的判断发情 周期阶段的方法和标准的不同可能是导致结果差 异的主要原因。因此, 小鼠发情阶段的鉴定, 是进 行小鼠有效超排的关键之一。

本研究以获得高效超排效果为主要目的, 结合 小鼠阴门状态和阴道脱落细胞涂片观察, 判断其发 情周期阶段, 并以卵巢组织切片验证其发情周期阶 段的准确性，进而在小鼠发情周期不同阶段进行小 鼠超排，追踪超排后卵泡发育情况和胚胎回收结果， 确定超排开始的适宜发情周期阶段，为进一步提高 小鼠超排效果及调整超排时间、满足空间胚胎发育 研究的早期胚胎需求提供基础资料。

\section{1 材料与方法}

\section{1 实验动物}

昆明系小鼠，购自第四军医大学实验动物中 心。饲养间保持 $13 \mathrm{~h} / 11 \mathrm{~h}$ 的明暗周期变化 (7:00-20:00 光照), 自由采食、饮水。雌鼠体重 $25 \mathrm{~g}$, 雄鼠体重 $35 \mathrm{~g}$ 时用于试验。

\section{2 试剂}

多聚甲醛、曙红 Y 及中性树胶购自国药集团化 学试剂有限公司; 二甲苯及氯化钠购自天津博迪化 工股份有限公司; 苏木色精购自上海青析化工科技 有限公司; 无水乙醇购自西安三浦化学试剂有限公 司; 鳞片状切片石蜡 (熔点 $58 \sim 60{ }^{\circ} \mathrm{C}$, LEICA
39601095); 切片石蜡(熔点 $51 \sim 55{ }^{\circ} \mathrm{C}$ ) 购自上海标 本模型厂; 孕马血清促性腺激素 (pregnant mare serum gonadotropin, PMSG)及人线毛膜促性腺激素 (human chorionic gonadotrophin, hCG)购自宁波第二 激素厂; 胎牛血清(fetal bovine serum, FBS, GIBCO 16000-044); 胚胎操作液(添加 5\%FBS 的改良杜氏 磷酸盐缓冲液(modified Dulbecco's phosphate buffer solution, mDPBS)), 使用 SIGMA 试剂和超纯水自制。

\section{3 小鼠阴门状态观察}

于超排当天 16: 00 , 固定雌鼠并翻提尾巴露出 阴门，观察其阴门开张、阴门黏膜颜色及外阴肿胀 情况，根据阴门状态观察结果将小鼠的发情周期阶 段分为发情前期、发情期、发情后期和间情期，并 对阴门状态进行近距拍照。参考 Nagy et al(2002)所 著《小鼠肧胎操作实验手册》及作者实验室以往的 试验总结，根据阴门状态判定小鼠发情周期阶段的 主要依据为: 发情前期小鼠阴道口应未开张或微开 张、稍湿润，有少量分泌物，分泌物清亮，阴门黏膜 浅红色，阴门皱譬轻微红肿; 发情期小鼠阴道口开 张、较湿润，有少量浆液状或稍粘稠分泌物，阴门 黏膜红色较深, 皱譬明显肿胀; 发情后期小鼠阴道 口松驰或已关闭, 其周边有少量浆液状或已凝固的 白色分泌物，阴门黏膜颜色变为肉红色至白色，阴 门色譬肿胀逐渐消退; 间情期小鼠阴道口紧闭、无 分泌物，阴门黏膜呈苍白色，阴门皱譬肿胀完全消 退。

\section{4 小鼠阴道脱落细胞涂片制作与观察}

采用阴门状态观察法挑选处于发情周期不同 阶段的雌鼠，制作阴道脱落细胞涂片。雌鼠保定、 暴露阴道口, 将吸有少量生理盐水的滴管伸入阴道 口轻轻冲洗阴道, 反复冲吸几次后, 回吸一滴并滴 于载玻片上，制作涂片。进行 H.E. 染色(苏木精染色 $1 \mathrm{~min}$ 、伊红染色 $50 \mathrm{~s}$ ), 随后冲片, 干燥, 镜检、显 微摄影。通过阴道脱落细胞涂片观察, 对小鼠发情 周期阶段进行进一步鉴定。发情前期阴道脱落细胞 以部分角化上皮细胞为主; 发情期阴道脱落细胞以 完全角化上皮细胞为主; 发情后期以白细胞和中间 层细胞为主; 间情期为少量白细胞与中间层细胞 (Bekyurek et al, 2002)。

\section{5 小鼠卵巢石蜡切片制作}

将已制作阴道脱落细胞涂片的小鼠处死，分离 其双侧卵巢, 剪去卵巢周围的结缔组织。将卵巢组 织浸泡于 $4 \%$ 多聚甲醛中 $24 \sim 48 \mathrm{~h}$, 脱水、透明、包 
埋, 制作连续石蜡切片(片厚 $7 \mu \mathrm{m})$, H.E. 染色, 中性 树胶封片, 镜检、显微摄影。通过对小鼠卵巢石蜡 切片的观察, 对阴门状态观察法和阴道脱落细胞涂 片法判定小鼠发情周期阶段的准确性进行进一步 验证。

\section{6 小鼠的超排、配种、胚胎采集}

在上述试验的基础上, 采用阴门观察法对处于 发情前期、发情期、发情后期和间情期的小鼠进行 超排处理, 每个阶段 30 只。超排程序为, 超排当天 (0 d) 16: 00 每只雌鼠腹腔注射 PMSG 10 IU, 48 h 后 $(2 \mathrm{~d})$ 腹腔注射 $\mathrm{hCG} 10 \mathrm{IU}$, 随即将超排雌鼠与单 笼饲养的雄鼠按照 $1: 1$ 比例合笼过夜配种。次日(3 d)上午 7:00 观察记录雌鼠阴门栓形成情况。每组 超排小鼠于注射 PMSG $24 \mathrm{~h}$ 和 $48 \mathrm{~h}$ 后(未注射 $\mathrm{hCG}$ ) 分别处死 3 只, 采集双侧卵巢制作石蜡切片、 H.E. 染色, 通过切片观察卵巢上卵泡发育情况。注射 PMSG $94 \mathrm{~h}$ 和 $120 \mathrm{~h}$ 后, 颈椎脱臼分别各处死超排 小鼠 12 只, 回收 2 细胞胚胎(输卵管)和 8 细胞及以 上发育阶段胚胎(输卵管和子宫角)。无菌分离子宫 角、输卵管和卵巢, 置于盛有胚胎操作液的表面皿 中进行清洗后更换表面皿。输卵管胚胎回收时, 先 用眼科剪剪断卵巢和输卵管之间的联系结构, 再剪 断子宫与输卵管联结处, 将输卵管转移到盛有胚胎 操作液的表面皿中, 置于实体显微镜载物台上, 在 30 倍镜下, 用一支眼科异物针固定输卵管, 另一支 异物针撕开输卵管, 直至将整个输卵管撕裂, 胚胎 会释放到胚胎操作液中, 在实体显微镜下检出胚胎; 子宫角胚胎回收时, 将子宫体及子宫角置于盛有胚 胎操作液的表面血中, 先用眼科剪纵向剪子宫角尖 端, 用吸有胚胎操作液的 $2 \mathrm{~mL}$ 一次性注射器从子 宫体开口插入针头冲洗子宫腔, 使胚胎随着液体流 动而被冲出子宫, 每侧用液体 $1.0 \sim 1.5 \mathrm{~mL}$, 之后再 重复冲洗一次, 在实体显微镜下从冲出液中检出胚 胎。检出胚胎用新鲜胚胎操作液清洗 3 次后, 于倒 置显微镜下观察胚胎的形态质量并分别计数。

\section{7 统计分析}

数据处理及差异性分析均在 SPSS11.0 软件中 进行。 $P<0.05$ 为差异显著, $P \geqslant 0.05$ 为差异不显著。

\section{2 结 果}

\section{1 小鼠发情周期不同阶段阴门外观}

观察小鼠阴门状态, 并根据阴门状态判断小鼠 发情周期阶段, 结果见图 1 。

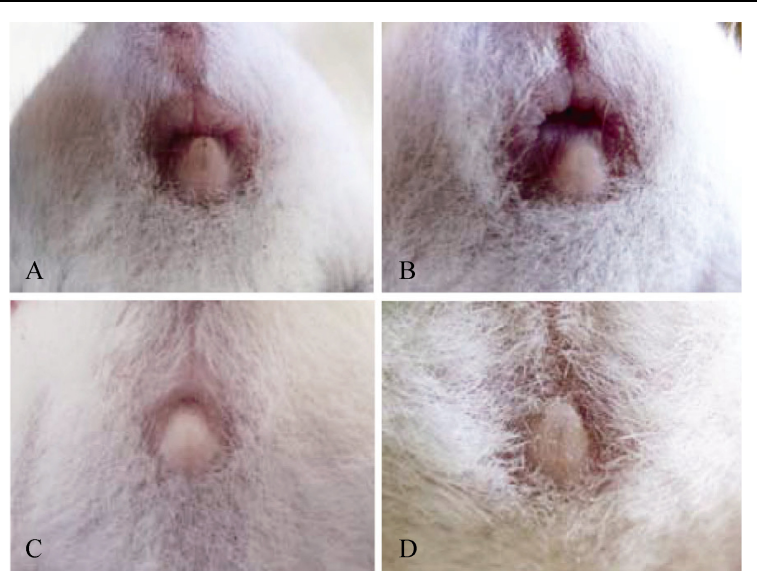

图 1 发情周期不同阶段阴门外观

Fig. 1 Pudendum appearance in different stages of the estrus cycle

A) 发情前期; B) 发情期; C) 发情后期; D) 间情期。

A) Proestrus; B) Oestrus; C) Metoestrus; D) Dioestrus.

\section{2 小鼠发情周期不同阶段阴道脱落细胞涂片观 察结果}

小鼠发情周期不同阶段阴道脱落细胞涂片见 图 2。处于发情前期的小鼠阴道脱落细胞以部分角 化上皮细胞为主, 有少量完全角化上皮细胞, 细胞 密度较小。其中, 部分角化上皮细胞为梭形或椭圆 形, 可见明显的深紫色固缩核或淡染的紫红色细胞 核, 细胞质呈浅紫色; 完全角化上皮细胞又称无核 角化上皮细胞, 为无规则多边形, 大而扁平, 无细 胞核, 细胞质呈浅红色(图 2A)。发情期小鼠阴道脱 落细胞绝大部分为完全角化上皮细胞, 数量较多, 如同堆积的落叶(图 2B)。发情后期小鼠的阴道脱落

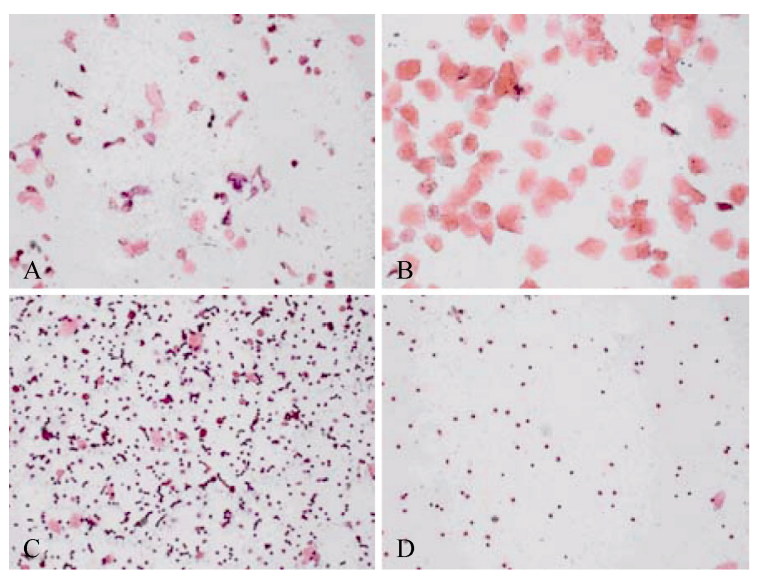

图 2 发情周期不同阶段阴道脱落细胞涂片 $(\times 200)$

Fig. 2 Vaginal epithelial cells in different stages of the estrus cycle $(\times 200)$

A) 发情前期; B) 发情期; C) 发情后期; D) 间情期。

A) Proestrus; B) Oestrus; C) Metoestrus; D) Dioestrus. 
细胞以白细胞为主, 间或少量中间层细胞和完全角 化上皮细胞。白细胞形态小而圆, 细胞核较大, 为 马蹄状或分叶状, 深紫色; 细胞质为浅紫红色。中 间层细胞呈鳞状, 可见深蓝色圆形细胞核, 胞质为 浅紫色(图 2C)。间情期小鼠阴道脱落细胞数量较少, 细胞种类以中间层细胞和白细胞为主, 偶尔可见完 全角化上皮细胞(图 2D)。

\section{3 小鼠发情周期不同阶段卵巢组织切片}

小鼠发情周期不同阶段卵巢组织切片见图 3。 处于发情前期的小鼠，其卵巢皮质部分布较多发育 中的有腔卵泡, 卵泡腔体积较大, 但卵泡未突出于 卵巢表面(图 3A)。处于发情期的小鼠, 其卵巢皮质 部边缘分布较多的有腔卵泡, 卵泡腔体积较大且卵 泡壁较薄, 多数突出于卵巢表面(图 3B); 处于发情 后期的小鼠, 其卵巢切面上主要为黄体分布, 少见 有腔卵泡(图 3C); 处于间情期的小鼠, 其卵巢切面 上可见较多黄体, 在黄体之间分布有不同发育阶段 的腔前卵泡或小腔卵泡(图 3D)。

\section{4 发情周期不同阶段小鼠超排后不同时间卵泡 发育情况}

发情周期不同阶段小鼠超排后不同时间卵巢 卵泡发育情况见图 4。发情前期的小鼠在注射 PMSG $24 \mathrm{~h}$ 后, 卵巢切面可见数量较多的发育中的 有腔卵泡分布, 但基本未突出于卵巢表面, 少见黄 体(图 4A1); 注射 PMSG $48 \mathrm{~h}$ 后, 卵巢皮质部边缘 可见较多的有腔卵泡, 卵泡腔体积较大, 大部分卵 泡突出于卵巢表面, 少见黄体(图 4A2)。发情期小鼠 注射 PMSG $24 \mathrm{~h}$ 后, 其卵巢皮质部浅层可见多个卵
泡，卵泡腔体积较大，部分卵泡向卵巢表面突出， 少见黄体(图 4B1); 注射 PMSG $48 \mathrm{~h}$ 后, 部分大的 卵泡突出于卵巢表面，卵巢皮质部可见新形成的黄 体(图 4B2)。发情后期小鼠注射 PMSG $24 \mathrm{~h}$ 后, 其 卵巢切面上可见有少数腔前卵泡、小腔卵泡和多个 黄体(图 4C1); 注射 PMSG $48 \mathrm{~h}$ 后，可见卵巢切面 上有少数有腔卵泡和多个黄体(图 4C2)。间情期小 鼠注射 PMSG $24 \mathrm{~h}$ 后，卵巢皮质部可见多个腔前卵 泡和发育中的有腔卵泡以及多个黄体(图 4D1); 注 射 PMSG $48 \mathrm{~h}$ 后，卵巢皮质部浅层可见多个大的有 腔卵泡，卵泡壁变薄，部分卵泡突出于卵巢表面， 可见较少黄体(图 4D2)。

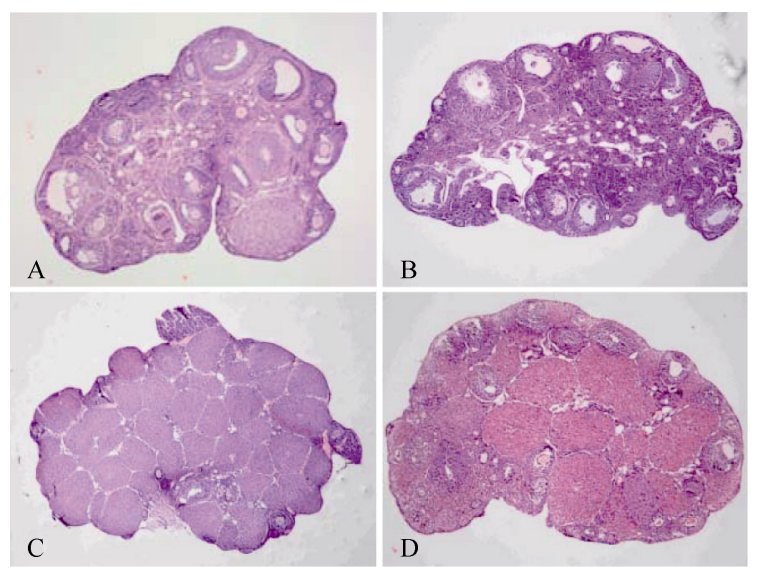

图 3 发情周期不同阶段卵巢组织切片 $(\times 40)$

Fig. 3 Histological sections of ovaries in different stages of the estrus cycle

A) 发情前期; B) 发情期; C) 发情后期; D) 间情期。

A) Proestrus; B) Oestrus; C) Metoestrus; D) Dioestrus.
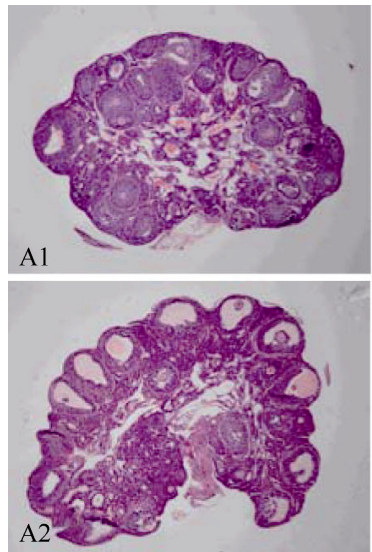
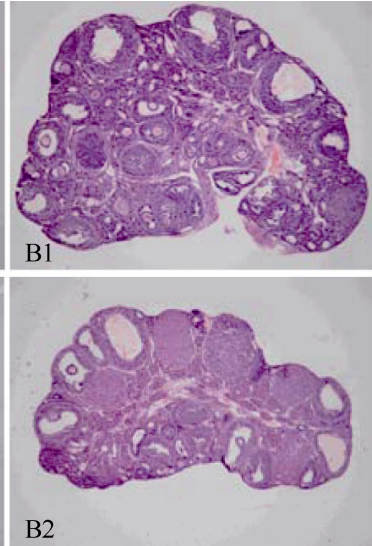
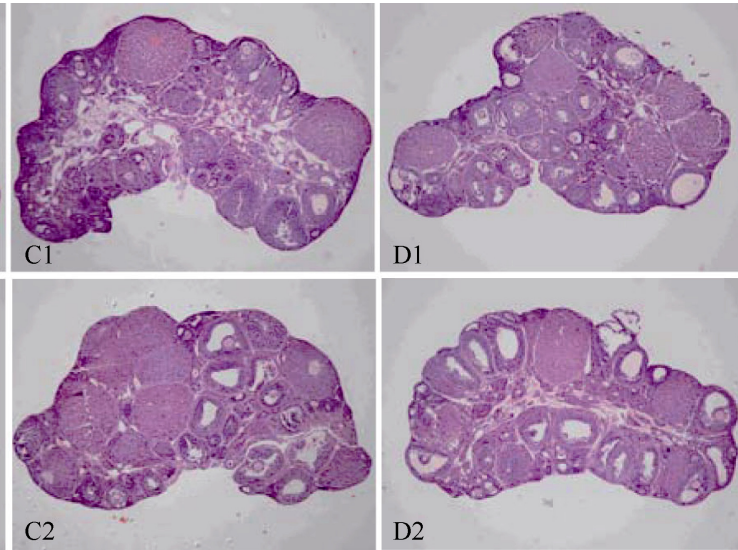

图 4 发情周期不同阶段注射 PMSG 后的卵巢组织切片 $(\times 40)$

Fig. 4 Histological sections of ovaries injected with PMSG in different stages of the estrus cycle $(\times 40)$ A) 发情前期; B) 发情期; C) 发情后期; D) 间情期; 1) PMSG 注射后 $24 \mathrm{~h}$; 2) PMSG 注射后 $48 \mathrm{~h}$ 。

A) Proestrus; B) Oestrus; C) Metoestrus; D) Dioestrus; 1) Twenty-four hours after injection of PMSG; 2) Forty-eight hours after injection of PMSG. 
2.5 发情周期不同阶段小鼠超排配种后的胚胎回 收结果

发情周期不同阶段小鼠超排配种后，分别在注
射 PMSG $94 \mathrm{~h}$ 和 $120 \mathrm{~h}$ 回收胚胎, 并分别计数发育 到 2 细胞(或以上阶段, 以 2 细胞计)和 8 细胞(或以 上阶段, 以 8 细胞计)胚胎数量, 结果见表 1 和表 2 。

表 1 发情周期不同阶段超排小鼠 PMSG 注射后 94 h 2 细胞胚胎回收结果

Tab. 1 The 2-cell embryo collection result at $94 \mathrm{~h}$ after PMSG injected of superovulation mouse in different stages of estrus cycle

\begin{tabular}{|c|c|c|c|c|}
\hline $\begin{array}{c}\text { 超排开始时的发情周期阶段 } \\
\text { Beginning of superovulation } \\
\text { estrus cycle stage }\end{array}$ & $\begin{array}{l}\text { 超排鼠/只 } \\
\text { Number of } \\
\text { superovulated mice }\end{array}$ & $\begin{array}{l}\text { 见栓鼠/只 }(\%) \\
\text { Number of mice with } \\
\text { vaginal plud }\end{array}$ & $\begin{array}{c}\text { 回收到 } 2 \text { 细胞胚的小鼠数/只 }(\%) \\
\text { Number of mice } 2 \text {-cell embryos } \\
\text { were collected from }\end{array}$ & $\begin{array}{c}\text { 超排小鼠 } 2 \text { 细胞胚胎平均数 }(m e a n \pm S D) \\
\text { Avere number of 2-cell embryos in } \\
\text { superovulated mice }\end{array}$ \\
\hline $\begin{array}{l}\text { 发情前期 } \\
\text { Proestrus }\end{array}$ & 12 & $11(91.67)^{\mathrm{a}}$ & $11(91.67)^{\mathrm{a}}$ & $36.92 \pm 17.83^{\mathrm{a}}$ \\
\hline $\begin{array}{l}\text { 发情期 } \\
\text { Oestrus }\end{array}$ & 12 & $9(75.00)^{\mathrm{a}}$ & $9(75.00)^{\mathrm{ab}}$ & $27.25 \pm 20.87^{\mathrm{ab}}$ \\
\hline $\begin{array}{l}\text { 发情后期 } \\
\text { Metoestrus }\end{array}$ & 12 & $4(33.33)^{b}$ & $4(33.33)^{c}$ & $8.33 \pm 17.05^{\mathrm{c}}$ \\
\hline $\begin{array}{l}\text { 间情期 } \\
\text { Dioestrus }\end{array}$ & 12 & $8(66.67)^{\mathrm{ab}}$ & $6(50.00)^{\mathrm{bc}}$ & $14.33 \pm 17.33^{\mathrm{bc}}$ \\
\hline
\end{tabular}

各栏组间上标字母相同者差异不显著, 不同者差异显著。

Appearance of the same letter means there is no significant difference among the groups while different letters mean there is significant difference.

表 2 发情周期不同阶段超排小鼠 PMSG 注射后 120 h 8 细胞胚胎回收结果

Tab. 2 The 8-cell embryo collection results at $120 \mathrm{~h}$ after PMSG injection in different stages of the estrus cycle

\begin{tabular}{|c|c|c|c|c|}
\hline $\begin{array}{c}\text { 超排开始时的发情周期阶段 } \\
\text { Beginning of superovulation } \\
\text { estrus cycle stage }\end{array}$ & $\begin{array}{c}\text { 超排鼠/只 } \\
\text { Number of } \\
\text { superovulated mice }\end{array}$ & $\begin{array}{c}\text { 见栓鼠/只 }(\%) \\
\text { Number of mice } \\
\text { with vaginal plud }\end{array}$ & $\begin{array}{c}\text { 回收到 } 8 \text { 细胞胚的小鼠数/只 }(\%) \\
\text { Number of mice } 8 \text {-cell embryos } \\
\text { were collected from }\end{array}$ & $\begin{array}{c}\text { 超排小鼠 } 8 \text { 细胞胚胎平均数 }(\text { mean } \pm S D) \\
\text { Average number of } 8 \text {-cell embryos in } \\
\text { superovulated mice }\end{array}$ \\
\hline $\begin{array}{l}\text { 发情前期 } \\
\text { Proestrus }\end{array}$ & 12 & $10(83.33)^{\mathrm{a}}$ & $10(83.33)^{\mathrm{a}}$ & $26.42 \pm 17.67^{\mathrm{a}}$ \\
\hline $\begin{array}{l}\text { 发情期 } \\
\text { Oestrus }\end{array}$ & 12 & $8(66.67)^{a b}$ & $8(66.67)^{\mathrm{ab}}$ & $18.33 \pm 14.57^{\mathrm{ab}}$ \\
\hline $\begin{array}{l}\text { 发情后期 } \\
\text { Metoestrus }\end{array}$ & 12 & $5(41.67)^{b}$ & $4(25.00)^{b}$ & $6.58 \pm 10.68^{b}$ \\
\hline $\begin{array}{c}\text { 间情期 } \\
\text { Dioestrus }\end{array}$ & 12 & $8(66.67)^{a b}$ & $7(58.33)^{\mathrm{ab}}$ & $11.08 \pm 12.12^{\mathrm{b}}$ \\
\hline
\end{tabular}

各栏组间上标字母相同者差异不显著，不同者差异显著。

Appearance of the same letter means there is no significant difference among the groups while different letters mean there is significant difference.

由表 1 和表 2 可以看出, 发情周期不同阶段超 排小鼠的见栓率、回收到胚胎的超排小鼠数和超排 小鼠 2 细胞胚胎和 8 细胞胚胎平均数均存在组间差 异。总体趋势为, 发情前期显著优于发情后期与间情 期 $(P<0.05)$, 并高于发情期, 但差异不显著 $(P>0.05)$ 。

\section{3 讨 论}

小鼠的发情周期一般为 4 $5 \mathrm{~d}$ (Tarín et al, 2002), 不同阶段卵泡的不同发育状态会直接影响超排效 果。所以, 准确判断小鼠发情周期阶段, 并在适宜 阶段进行超数排卵, 对获得有效超排结果具有重要 意义。小鼠发情阶段的鉴定方法, 目前常用的有阴 门及其周围组织变化观察法和阴道脱落细胞涂片 观察法(Goldman et al, 2007; Tsiligianni et al, 2004)。 相对于小鼠阴门外观变化的观察, 阴道脱落细胞是 反应卵巢卵泡发育活动的较早且较准确的迹象, 以 上两种方法相结合可有效判断小鼠发情周期阶段
(Kopp et al, 2006)。本研究首先采取阴门观察法初步 判断小鼠的发情周期阶段，同时采集阴道脱落细胞 制作涂片并镜检作进一步判断，最后采集卵巢制作 组织切片, 观察卵泡及黄体的发育与消退情况, 对 小鼠阴门状态观察法和阴道脱落细胞涂片法所判 定的发情周期阶段准确性进行进一步验证。结果表 明，阴门皱譬较为肿胀，黏膜浅红，阴道口微张且 有清亮分泌物等为发情前期状态(图 1A), 其阴道脱 落细胞以部分角化上皮细胞为主，含少量完全角化 上皮细胞(图 2A); 卵巢组织切片可见大部分卵巢切 面分布有较多发育中的有腔卵泡，卵泡腔体积较大， 但卵泡未突出于卵巢表面(图 3A)。阴门皱譬明显肿 胀，黏膜呈鲜红色，阴道口开张，有少量浆液状或 粘稠分泌物等为发情期状态(图 1B), 其阴道脱落细 胞绝大部分为完全角化上皮细胞(图 2B); 卵巢切面 分布较多的有腔卵泡, 卵泡腔体积较大且卵泡壁较 薄, 多数突出于卵巢表面(图 3B)。阴道口松驰或已 
关闭，阴门黏膜颜色较浅且肿胀逐渐消退，周边有 少量浆液状或已凝固的白色分泌物等状态为发情 后期(图 1C), 其阴道脱落细胞以白细胞为主, 间有 少量中间层细胞和完全角化上皮细胞(图 2C); 卵巢 切面主要为黄体分布(图 3C)。阴门皱譬不肿胀, 黏 膜苍白色, 阴道口紧闭无分泌物等状态为间情期 (图 1D), 阴道脱落细胞数量较少, 以中间层细胞和 白细胞为主(图 2D); 卵巢切面可见较多黄体, 且黄 体之间分布有不同发育阶段的腔前卵泡或小腔卵 泡(图 3D)。由以上结果可见, 当小鼠卵泡和黄体发 育及消退呈周期性变化时, 卵泡颗粒细胞分泌的雌 激素和黄体细胞分泌的孕激素也随之呈周期性的 改变, 引起以阴门黏膜肿胀消长、黏膜颜色及阴道 分泌物的改变为主要特征的阴门及其周围组织的 周期性变化。而阴道黏膜上皮细胞在激素作用下, 呈周期性的增殖、成熟及脱落, 使阴道脱落细胞(如 部分角化上皮细胞、完全角化上皮细胞、中间层细 胞等)的类型和数量表现周期性变化(Catchpole et al, 2003)。同时, 发情周期中发生的周期性阴道分泌物 的增加与减少以及阴门的开张与闭合导致阴道酸 性环境的改变, 使阴道细胞类群中白细胞的数量表 现周期性的增减变化(Zhang et al, 2006)。

在上述研究的基础上, 对阴门观察法配合阴道 脱落细胞涂片判断发情周期阶段的小鼠, 分别于发 情前期、发情期、发情后期和间情期进行超排处理。 在注射 PMSG 后 $24 \mathrm{~h}$ 和 $48 \mathrm{~h}$ (未注射 $\mathrm{hCG}$ ), 分别采 集超排小鼠卵巢制作组织切片, 追踪超排后卵泡发 育情况; 对完成超排注射程序并配种的小鼠, 分别 于注射 PMSG $94 \mathrm{~h}$ 和 $120 \mathrm{~h}$ 处死、回收胚胎, 并分 别计数发育到 2 细胞(或以上阶段)和 8 细胞(或以上 阶段)胚胎数量, 比较发情周期不同阶段超排小鼠 的超排、受精及胚胎发育情况(注: 实验室尚未发表 的超排小鼠胚胎发育时程研究证明, 在注射 PMSG $94 \mathrm{~h}$ 和 $120 \mathrm{~h}$ 后, 2 细胞(或以上阶段)和 8 细胞(或以 上阶段)胚胎比例达到峰值, 故本研究选择这两个 时段分别评价受精卵发育到 2 细胞和 8 细胞阶段的 数量)。结果表明, 发情前期小鼠在注射 PMSG $24 \mathrm{~h}$ 后, 卵巢切面发育中的有腔卵泡数量较多, 但尚未 突出于卵巢表面(图 4A1); 注射 PMSG $48 \mathrm{~h}$ 后, 卵 巢切面边缘可见较多有腔卵泡, 卵泡腔体积较大, 且大部分卵泡突出于卵巢表面(图 4A2)。说明由于 发情前期小鼠卵巢上有腔卵泡数量较多, 在主要起 促进有腔卵泡生长发育的促性腺激素( $\mathrm{PMSG}$ )作用
下，多个有腔卵泡进一步生长发育成熟(Fortune, 2003), 并可能会在促进卵泡进一步成熟并排卵的 促性腺激素( $\mathrm{hCG}$ )作用下最后发育成熟并排卵, 获 得较好的超排效果。 2 细胞胚胎和 8 细胞胚胎回收 结果也验证了卵泡发育的组织学追踪结果。对于发 情期小鼠, 在注射 PMSG $24 \mathrm{~h}$ 后, 卵巢组织切面可 见多个成熟卵泡(图 4B1), 并在注射 PMSG $48 \mathrm{~h}$ 后, 已有部分成熟卵泡排卵、形成黄体，而另有部分卵 泡陆续发育到三级卵泡和成熟卵泡阶段(图 4B2)。 在这种情况下, 虽然也可能会获得较好的超排效果, 但由于出现超排程序中尚未注射排卵激素时即已 发生部分卵泡的排卵，而造成排卵不整齐，受精后 胚胎发育阶段不整齐, 甚至使过早排卵的卵母细胞 失去受精能力, 而使正常发育的胚胎数量减少。该 阶段小鼠胚胎回收结果表明, 2 细胞胚胎和 8 细胞胚 胎回收数量均低于发情前期超排小鼠, 但差异不显 著 $(P>0.05)$ 。发情后期进行超排的小鼠，在注射 PMSG $24 \mathrm{~h}$ 后, 其卵巢切面仅见少数腔前卵泡、小 腔卵泡和多个黄体(图 4C1); 注射 PMSG $48 \mathrm{~h}$ 后, 则有少数有腔卵泡和多个黄体(图 4C2)。这说明在 这一时期开始超排, 能够接受外源性促性腺激素刺 激效应的有腔卵泡数量较少, 不足以引起有效的超 排结果。该阶段小鼠胚胎回收结果也说明了卵泡发 育的追踪结果, 其 2 细胞和 8 细胞回收数均显著低 于发情前期超排小鼠 $(P<0.05)$, 同时 2 细胞回收数 显著低于发情期超排小鼠。间情期小鼠超排注射 PMSG $24 \mathrm{~h}$ 后, 卵巢切面可见多个腔前卵泡和发育 中的有腔卵泡，以及多个黄体(图 4D1); 注射 PMSG $48 \mathrm{~h}$ 后，卵巢皮质部浅层可见多个大的有腔卵泡， 卵泡壁变薄, 部分卵泡突出于卵巢表面, 可见较少 黄体(图 4D2)。这说明在这一阶段开始超排的小鼠, 由于卵巢上仍然存在黄体, 并开始出现数量较多的 腔前卵泡和小的有腔卵泡，外源性促性腺激素可诱 导有腔卵泡进一步生长发育并成熟, 从而起到一定 的超排效果。胚胎回收结果表明, 其超排结果显著 低于发情前期小鼠 $(P<0.05)$, 虽与发情期小鼠差异 不显著, 但正常胚胎回收数明显偏低。

该结果说明，小鼠发情周期阴门状态和阴道脱 落细胞类型的变化能够在一定程度上反映卵巢上 卵泡发育和黄体形成与消退的动态变化, 即通过阴 门状态观察和阴道脱落细胞涂片观察, 能够在一定 程度上判断卵巢上卵泡发育和黄体形成与消退的 动态变化, 可以作为判断小鼠发情周期阶段的依 
据。超排后 $24 \mathrm{~h}$ 和 $48 \mathrm{~h}$ 的卵泡发育追踪结果和之 后的胚胎回收结果说明，处于发情周期不同阶段的 小鼠超排后，其卵泡生长发育、成熟规律以及胚胎
回收结果存在明显差异，其中发情前期小鼠超排后 卵泡发育规律、正常发育成熟的卵泡数量及肧胎回 收数量较为理想，是适宜超排的发情周期阶段。

\section{参考文献:}

Bekyurek T, Liman N, Bayram G. 2002. Diagnosis of sexual cycle by means of vaginal smear method in the chinchilla (Chinchilla lanigera) [J]. Lab Anim, 36(1): 51-60.

Brooke DA, Orsi NM, Ainscough JFX, Holwell SE, Markham AF, Coletta PL. 2007. Human menopausal and pregnant mare serum gonadotrophins in murine superovulation regimens for transgenic applications [J]. Theriogenology, 67(8): 1409-1413.

Catchpole HR, Engel MB, Jordan SL. 2003. A microprobe study of element distribution in vaginal epithelial cells of the rat [J]. Cell Biol Int, 27(4): 355-359.

Chen YH, Men HS, Zhou XL, He XC. 1991. The study of bovine embryo transfer in Yunnan [J]. Zool Res, 12(4): 381-385. [陈云鹤, 门红升, 周 瑆良, 和协超. 1991. 云南省奶牛胚胎移植试验, 动物学研究, 12(4): 381-385.]

Cui YR, Jin H, Du CY, Wang CY, Chen H, Zhang QX. 2012. Effecting factor's analysis of superovulation in Kunming mouse [J]. Prog Vet Med, 33(2): 55-57. [崔元戎, 金辉, 杜春艳, 王纯耀, 陈辉, 张钦宪. 2012. 昆明鼠超数排卵影响因素研究. 动物医学进展, 33(2): 55-57.]

Ding F, Zhou HL, Liu Y, Ma L, Su Y, Du L. 2007. Effects of glucose on development of ICR mouse embryos in vitro [J]. Zool Res, 28(5): 501-506. [丁芳, 周红林, 刘洋, 马兰, 苏芗, 杜玲. 2007. 葡萄糖对 ICR 小鼠胚胎体外发育的影响. 动物学研究, 28(5): 501-506.]

Fortune JE. 2003. The early stages of follicular development: activation of primordial follicles and growth of preantral follicles [J]. Anim Reprod Sci, 78(3-4): 135-163.

Fu WD, Sun YC, Suo L, Gao JM. 2005. Observation of estrous cycle and choice of optimal superovulation time in mice [J]. J Beijing Agric Coll, 20(2): 19-21. [傅文栋，孙玉成，索伦，高建明. 2005. 小鼠发情周期 观察与最佳超排时期的确定. 北京农学院学报, 20(2): 19-21.]

Goldman JM, Murr AS, Cooper RL. 2007. The rodent estrous cycle: characterization of vaginal cytology and its utility in toxicological studies [J]. Birth Defects Res: Part B, 80(2): 84-97.

Guo QY, Jian ZJ, Liu XL, Yuan L, Kuang L. 2006. Research on influences of superovulation in different stage of estrous cycle about mouse [J]. $J$ Xinjiang Agric Univ, 29(3): 16-18. [ 郭庆勇, 简子健, 刘小兰, 袁龙, 况玲. 2006. 小鼠发情周期不同时期超数排卵效果的研究. 新疆农 业大学学报, 29(3): 16-18.]

He XC, Ji SH, Zhang X, He ZX, Wen JK, Ji WZ. 1999. Comparison between GnRH and PGF2 a on estrus synchronization in dairy cows[J].
Zool Res, 20(5): 332-335. [和协超, 纪少珲, 张僖, 和占星, 文际坤, 季维智. 1999. 奶牛胚胎移植中 GnRH、PGF2 a 同期发情处理效果 的比较. 动物学研究, 20(5): 332-335.]

He ZX, He XC, Luo ZR, Zhu FX, Lingmu DX, Chuang XH, Yin AQ, Huang XS. 2005. Experiments on synchronous estrus, superovulation and embryo transfer in buffaloes of Yunnan [J]. Zool Res, 26(1): 106-111. [和占星, 和协超, 罗在仁, 朱芳贤, 铃木达行, 创向辉, 尹安强, 黄 晓松. 2005. 云南水牛的同期发情、超数排卵和胚胎移植试验. 动物 学研究, 26(1): 106-111.]

Kopp C, Ressel V, Wigger E, Tobler I. 2006. Influence of estrus cycle and ageing on activity patterns in two inbred mouse strains [J]. Behav Brain Res, 167(1): 165-174.

Martín-Coello J, González R, Crespo C, Gomendio M, Roldan ERS. 2008. Superovulation and in vitro oocyte maturation in three species of mice (Mus musculus, Mus spretus and Mus spicilegus) [J]. Theriogenology, 70(6): 1004-1013.

Nagy A, Gertsenstein M, Vintersten K, Behringer R. 2002. Manipulating the Mouse Embryo. 3rd ed. [M]. LongIsland: Cold Spring Harbor Laboratory Press, 147.

Palermo R. 2007. Differential actions of FSH and $\mathrm{LH}$ during folliculogenesis [J]. Reprod Biomed Online, 15(3): 326-337.

Redian OE, Amstislavsky SY, Maksimovsky LF. 1994. Induction of superovulation in DD mice at different stages of the oestrous cycle [J]. $J$ Reprod Fertil, 102(2): 263-267.

Tarín JJ, Pérez-Albalá S, Cano A. 2002. Stage of the estrous cycle at the time of pregnant mare's serum gonadotropin injection affects the quality of ovulated oocytes in the mouse [J]. Mol Reprod Dev, 61(3): 398-405.

Tsiligianni T, Saratsi A, Besenfelder U, Anastasiadis A, Vainas E, Saratsis P, Brem G. 2004. The use of cytological examination of vaginal smears (CEVS) in the selection of rabbits for superovulation [J]. Theriogenology, 61(6): 989-995

Yang PX. 2007. Studies of Toxicity of Aroclor 1254 on Early Mouse Embryo Development in Vitro [D]. MSc thesis, Northwest A\&F University. [杨培先. 2007. Aroclor 1254 对小鼠早期胚胎体外发育毒 性的研究 [D]. 硕士学位论文, 西北农林科技大学.]

Zhang S, Wang X, Wei XB, Tan JH. 2006. Observation on the vaginal smear photographs for each stage of estrus cycle in rats [J]. Prog Vet Med, 27(2): 69-72. [张森, 王新, 韦旭斌, 谭建华. 2006. 大鼠发情周期各 阶段的阴道细胞变化观察. 动物医学进展, 27(2): 69-72.] 